OPEN ACCESS

Edited by:

Raúl Navarro,

University of Castilla-La Mancha,

Spain

Reviewed by:

Amanda M. Dettmer,

Yale University, United States

Gianluca Serafini,

San Martino Hospital (IRCCS), Italy

*Correspondence:

Marjolijn M. Vermande

m.m.vermande@uu.nl

${ }^{\dagger}$ These authors share first authorship

Specialty section:

This article was submitted to Educational Psychology,

a section of the journal

Frontiers in Psychology

Received: 18 July 2020 Accepted: 22 September 2020 Published: 03 November 2020

Citation: Vermande MM and Sterck EHM (2020) How to Get the Biggest Slice of the Cake. A Comparative View of Social Behaviour and Resource Access in

Human Children and

Nonhuman Primates.

Front. Psychol. 11:584815. doi: 10.3389/fpsyg.2020.584815

\section{How to Get the Biggest Slice of the Cake. A Comparative View of Social Behaviour and Resource Access in Human Children and Nonhuman Primates}

\author{
Marjolijn M. Vermande ${ }^{1 * t}$ and Elisabeth H. M. Sterck $k^{2,3 \dagger}$ \\ ${ }^{1}$ Department of Child and Adolescent Studies, Utrecht University, Utrecht, Netherlands, ${ }^{2}$ Department of Biology, Utrecht \\ University, Utrecht, Netherlands, ${ }^{3}$ Department of Animal Science, Biomedical Research Centre (BPRC), Rijswijk, Netherlands
}

Social complexity results from engaging in different classes of social behaviour. The presence of different classes of social behaviour is reflected in multidimensional concepts of social asymmetry, found in both human and nonhuman primates. Based on an overview of such concepts, we propose that three classes of social behaviour are involved in having access to scarce and desired resources: next to aggressive and affiliative behaviour, also action indicating behaviour (i.e., inspire another individual to follow one's example or intentions) may lead to resource access. Studies with nonhuman primate and human children show that the contribution of aggression and affiliation to resource access has been widely documented and that there is initial support for action indicating behaviour. In addition, the studies show similarities and differences in conceptualization and approach that may inspire future research. Future research should address the (in)dependency of the behavioural dimensions, their relative importance, individual differences in combined expression and the type of resources accessed. Only a multi-dimensional view on behaviour leading to resource access will highlight the benefits of social complexity.

Keywords: social hierarchy, social behaviour, alternative strategies, resource access, resource control, dominance, bonds, leadership

\section{INTRODUCTION}

Primates, both human and nonhuman, are characterized by complex social behaviours encompassing different classes of social behaviour. We explore how social complexity may be beneficial in accessing resources. In both human and nonhuman primates, unequal resource access is a pervasive feature of groups (Sapolsky, 2005). Individuals strive toward survival and reproduction in an environment that typically contains limited resources, which causes within-group competition (van Schaik, 1989; Pellegrini, 2008). Resources enable optimal reproduction and thus, biological fitness. However, in literature on human children, resources are not always directly linked to fitness, but often refer to coveted goods, partners, or features. Different types of resources can be distinguished, including material (e.g., food, treats, shelter, territory, toys, and money) and social (e.g., alliance, knowledge, tolerance, and affection) resources (Charlesworth, 1996; Keltner et al., 2003; Hawley, 2007; Pellegrini et al., 2011). Resources of one form (e.g., money, alliances) can be used as means of obtaining resources of another form (Charlesworth, 1996). Group members usually differ in 
their ability and motivation to prevail in resource competition (Charlesworth, 1996) and individuals may access resources by using different social strategies, based on different classes of social behaviour (Hawley, 1999; Overduin-de Vries et al., 2020).

Traditionally, aggression and the ensuing dominance relationships are considered to provide preferential access to resources (Sussman et al., 2005). This implicitly assumes that behaviour used for resource access is found in one behaviour dimension. More recently, however, it has been acknowledged that affiliative behaviours and eventual "bonds" [also called "good relationships", and (among non-kin) "friendships"; Silk, 2002; Massen et al., 2010; Seyfarth and Cheney, 2012] may be effective as well in both humans and animals (Sussman et al., 2005). This leads to the proposal that social behaviour used for resource access is multidimensional. In particular in developmental psychology this view is commonly held and investigated (Santos and Vaughn, 2018). Moreover, we propose that a third class of social behaviour, namely inspiring the direction of action (indicating action) by esteemed individuals, may also lead to resource access.

The link between access to limited resources and social behaviours has been investigated in humans and animals, yet the concepts of social behaviour resulting in asymmetric resource access and findings of these two research fields are rarely compared directly. Although the study of resource access in developmental psychology originally has been influenced by sociobiology and ethology (e.g., Strayer and Strayer, 1976; Charlesworth, 1988; Hawley, 1999), there are some differences in approach. By identifying similarities, differences, and research gaps, we aim to stimulate research into different ways to access resources in humans and animals. More specific, we focus on comparing research on human children and nonhuman primates (further called primates) for three reasons: first, human and primate social behaviours may be similar when they are conserved and can be traced back to common ancestral behaviours; second, much detail of and variation in both primate and human children's social behaviours is known, allowing a comparison; and third, the relationship between social behaviours and resource access has been topic of recent research on both human children and primates, providing theoretical and empirical frameworks that can be compared.

The central questions of the present conceptual analysis are: (1) whether three rather than two classes of social behaviour are conceptually linked to resource access for children and primates, (2) what empirical evidence relates classes of social behaviours to resource access in human children and primates, (3) what resources are accessed, and (4) how the different classes of social behaviours relate to each other.

\section{CONCEPTUAL PROPOSAL: THREE CLASSES OF SOCIAL BEHAVIOURS CAN LEAD TO RESOURCE ACCESS}

\section{Multidimensional Concepts of Social Asymmetry}

There is no commonly accepted taxonomy of social asymmetry of individuals within groups. Many different concepts are used, both within and across disciplines (Henrich and Gil-White, 2001;
Watts, 2010; Table 1). Although social asymmetry is often discussed in terms of aggression (e.g., the traditional view of dominance in terms of power-submission relations in dyadic contest and group structure; Lewis, 2002), recent developments in both primatology and social sciences indicate that non-agonistic classes of social behaviour may also be effective in gaining a high position.

Several concepts can be interpreted as considering both aggressive and affiliative social behaviour. First, in developmental science, dominance has been recently defined as successful competition over resources in the presence of others (labelled resource control; Charlesworth, 1988; Hawley, 1999; Pellegrini, 2008; Stump et al., 2009). Resource control encompasses both aggressive and positive, socially acceptable behaviours [such as (promising) reciprocity and cooperation]. Note that this use of dominance to describe the outcome of behaviour contrasts with the one-dimensional use of dominance by biologists and early ethologically oriented developmental psychologists, who define dominance in terms of asymmetry in agonistic conflicts. Second (peer-perceived), popularity in child peer groups is characterized by power, prestige, or visibility (Cillessen and Marks, 2011) and correlates with resource control (Olthof et al., 2011; Vermande et al., 2018). Popularity results from the strategic use of antisocial (e.g., physical attacks, gossiping, and bullying) and prosocial (i.e., voluntary behaviour to benefit another individual; Eisenberg et al., 2010) behaviours (Cillessen, 2011). Third, the concept of social network centrality partially overlaps with both resource control and popularity in children (Hawley, 2007; Cillessen and Marks, 2011; Zarbatany et al., 2019). Actors who are the most important or the most prominent are usually located in strategic locations within the network (Wasserman and Faust, 1994). Social network centrality as an index of social asymmetry is usually measured using affiliation networks. It is associated with both prosocial (e.g., cooperation, leading, and joking) and antisocial (e.g., picking on, teasing, and disruptiveness) behaviours in both children (Farmer and Rodkin, 1996; Gest et al., 2001) and primates (Lehmann and Ross, 2011; Sueur et al., 2011). Fourth, power refers to the ability to direct or influence the behaviour of others (Keltner et al., 2003; Giordano et al., 2006). Although it is often associated with aggression and dominance, some scholars argue that aggression is not the only component of power in humans and animals (Lewis, 2002, 2018; Smith et al., 2016). In this approach, power has two components: dominance (i.e., power based upon force or the threat of force) and leverage (i.e., power based on resources that cannot be taken by force, such as fertilizable eggs, services, and coalitionary support; Lewis, 2002, 2018). When an individual has leverage over an inalienable resource, others will have to use alternative methods to dominance to obtain the resource. We propose that to get access to individuals with leverage (i.e., a social resource), affiliative behaviour will be enlisted. In this view, power concerns aggressive and affiliative social behaviour.

Several other concepts of social asymmetry are considering both aggressive and indicating action behaviour (i.e., inspire another individual to follow one's example or goals) rather than aggressive and affiliative behaviour. First, in humans, including young children, sometimes two subtypes of dominant personality - aggressive and social - have been identified. 
TABLE 1 | Multidimensional conceptualisations of social asymmetry, stressing either aggressive and affiliative behaviour or aggressive and action-indicating behaviour.

\section{Classes of social behaviour}

Concepts
Aggressive behaviour (inflicting damage or unpleasantness upon another individual)
Affiliative behaviour (binds individuals in (sub)groups by benefitting another individual)
Action indicating behaviour (inciting someone to follow his/her intention or example, because of the promise of success)
Dominance in terms of preferential access to scarce resources ("resource control"; Charlesworth, 1988; Hawley, 1999; Pellegrini, 2008)a

(Peer perceived) popularity: power, prestige, or visibility in the peer group (Cillessen, 2011) ${ }^{\mathrm{a}}$

Social network centrality: the most important or prominent actors within the network (Farmer and Rodkin, 1996; Sueur et al., 2011) a,b

Power: an asymmetrical dyadic relationship when preferences conflict (Lewis, 2002) ${ }^{a, b}$

Dominant personality: a personality trait focused on influencing others (Kalma et al., 1993) ${ }^{a}$

Status: a hierarchy of rewards and/or displays (Henrich and Gil-White, 2001; Chapais, 2015) a,b

Social hierarchy: influence over others (Fragale et al., 2011) a

Leadership: non-random differential influence on group behaviour of conspecifics (Smith et al., 2016)a,b
Aggression; coercive resource

control strategies

\section{Antisocial behaviour} (aggression, disruptiveness)

Antisocial behaviour

(aggression, disruptiveness)

Dominance (force or force threat)

Aggressive dominant individuals use aggression to persuade others

Power (force or force threat)

Power (the extent to which an individual can control others' outcomes by granting or withholding valued resources)

Dominance (coercion to control the behaviour of subordinates)
Co-operation and other forms of affiliation; prosocial (positively assertive) resource control strategies

Prosocial behaviour (voluntary behaviour to benefit someone else)

Prosocial behavioural (cooperative, leading)

\section{Leverage (based on inalienable} resources)

(in

Socially-oriented dominant individuals rely on reasoning in order to influence group decisions

Prestige (freely conferred deference, drawn from reputation, respect, and reverence)

Status (the extent to which an individual is respected, admired and highly regarded by others)

Visibility, knowledge, or other factors affecting voluntary decisions to follow or emulate (i.e., prestige)

"These conceptualisations have been applied to humans.

${ }^{b}$ These conceptualisations have been applied to nonhuman primates.

Both types demonstrate a focus on influencing others, but aggressive-dominant individuals use aggression (i.e., a more self-centred dictatorial type of strategy), whereas socially-oriented dominant individuals tend to make allies and try to sway others onto their side with solid arguments (Kalma et al., 1993; Cook et al., 2014). Second, status can be based on dominance (i.e., force or force threat) and on prestige (i.e., freely conferred deference; Henrich and Gil-White, 2001; Chapais, 2015; Cheng, 2020). Individuals with prestige achieve status by excelling in competences in valued domains (e.g., foraging success, physics, and basketball). Third, social hierarchy encompasses two potential influences over others, namely power, defined as "the extent to which an individual can control others' outcomes by granting or withholding valued resources," and status, defined as "the extent to which an individual is respected, admired and highly regarded by others" (Fragale et al., 2011, p. 767). Fourth, the related concept of leadership refers to non-random differential influence on group behaviour of conspecifics (Smith et al., 2016). Similar to power, differential influence may depend on dominance (i.e., coercion to control the behaviour of subordinates). Alternatively, it may depend on voluntary decisions to follow or emulate, for example, because of a leader's visibility or knowledge. In such cases, a leader has prestige (Smith et al., 2016).
In conclusion, the overview makes clear that scholars have not converged on a common taxonomy of social asymmetry and that the same concepts may have different meanings. More important for our analysis is that the overview suggests that three rather than two classes of social behaviour may underlie social asymmetry.

\section{Aggressive, Affiliative, and Action Indicating Behaviours May Provide Access to Resources}

As argued above, there are indications that three classes of social behaviour can result in social asymmetry and unequal resource access. These classes differ in how the receiving individual is affected and what type of social relationship (sensu Hinde, 1976, 1992) may result when these patterns are consistent over time (Figure 1). They may also provide access to specific types of resources. First, aggressive behaviour concerns the use of coercion to direct the behaviour of the receiving individual. The aggressive individual obtains preferential access to resources at the expense of the other individual. Consistent patterns in aggressive behaviour give rise to dominance relationships (as defined by biologists) at the dyadic level. Aggression will give access to resources (e.g., material resources like food and territories; or mating partners) by excluding competitors. Second, affiliative 


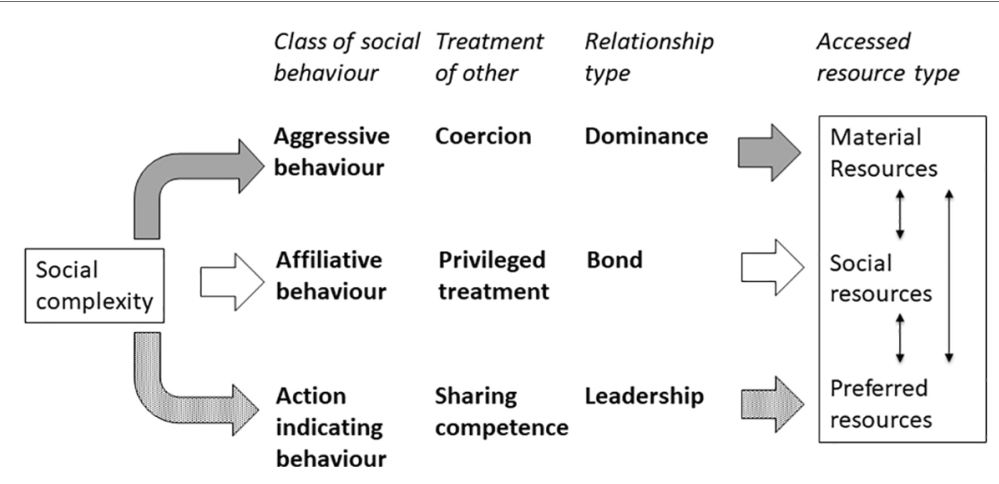

FIGURE 1 | Proposed relations between three classes of social behaviour, the effect of this social behaviour on the interaction partner, the ensuing relationship when the pattern is consistent, and the type of resources that may be accessed. Social complexity results from expressing different classes of social behaviour.

behaviour concerns giving the other individual a privileged treatment and therefore is beneficial to the receiver. The affiliative individual in turn can access resources that the receiver has to offer, such as sources of leverage (see section Multidimensional Concepts of Social Asymmetry). Both interaction partners may thus benefit and consistent patterns in affiliation lead to bonds, a proximate mechanism to achieve cooperation (de Waal and Luttrell, 1988) among kin (kin selection: Hamilton, 1964) and exchange of benefits among non-kin (reciprocal altruism: Trivers, 1971). The individual receiving affiliation can provide the affiliative individual with access to resources (e.g., social resources, such as support and tolerance, or material resources, such as toys). Third, an individual that exhibits action indicating behaviour can incite another individual to follow its example or intentions because of the promise of success. In this way, action indicating individuals can direct the behaviour of others to access preferred resources (e.g., doing a favourite game or visiting a favourite food tree, a common goal). Consistent patterns in indicating action identify leaders and followers. Thus, the three classes of social behaviour affect the receiving individuals in different ways and may lead to different types of social relationships (Figure 1). In addition, they all may provide access to resources, yet the type of resource may vary.

In the next section, we will explore whether empirical data support the conceptual idea that these three classes of social behaviour, that may be conserved in and shared by human children and primates, can contribute to resource access. If the three classes of social behaviour provide access to different resources, this indicates benefits of social complexity in both humans and primates.

\section{THREE CLASSES OF SOCIAL BEHAVIOUR AND RESOURCE ACCESS: EMPIRICAL LINKS}

In order to address the second research question, empirical studies on the relation between resource access and the three classes of social behaviour (aggressive, affiliative, and action indicating) are explored. While primatologists use observations of these behaviours, developmental psychologists use observations (often with pre-schoolers), but also peer reports (asking children as informants about their peers' behaviour and/or resource access), teacher reports (using teachers as informants), and self-reports (asking children about their own behaviour and/or resource access). Resource access may be measured at the level of specific resource utilization (e.g., seconds spent viewing a cartoon in a competitive movie viewer procedure, Charlesworth, 1996; access to a new toy, Hawley and Bowers, 2018; contact with the other sex at monthly school dances, Pellegrini, 2008). Quite often, however, resource control is assessed using rating scales with items covering several aspects of resource control (e.g., getting first hold of the nicest toys or the best gadgets, being the centre of attention in a group, and getting what she/he wants), resulting in a measure of a child's general resource access (e.g., Hawley, 2003; Olthof et al., 2011; Roseth et al., 2011; Ostrov and Guzzo, 2015). We will describe the types of resources accessed (research question 3 ) and the proposed relationships between the different classes of social behaviour leading to resource access (research question 4).

\section{Aggressive Behaviour}

Aggression is commonly defined as behaviour inflicting damage or other unpleasantness upon another individual. In the human literature, it is often added that the perpetrator must believe that the behaviour will harm the target (in order to distinguish aggression from accidental harm or the by-product of helpful actions such as pain due to a dental procedure), and that the target is motivated to avoid the behaviour (to distinguish aggression from e.g., sexual masochism; Anderson and Bushman, 2002). Aggression can be used to displace another individual from a location or coerce an individual into an action. Therefore, aggression may enhance resource access. There is ample support for the link between aggressive behaviour and resource access.

\section{Primates}

Both aggressive interactions and dominance relationships are used to access resources. Dominance relationships are discerned 
when aggressive interactions of a dyad lead to a predictable winner and loser. Preferential access need not necessarily require aggression, since subordinates defer to dominants or avoid them (Schaub, 1995). There is broad evidence indicating that aggression and dominance can give access to food (Ostner and Schülke, 2014; Overduin-de Vries et al., 2020) and to mating partners (Alberts, 2012). One study reports that aggression can also give access to support in between-group conflicts (Arseneau-Robar et al., 2016). The effects of dominance relationships are also visible in fitness outcomes that result from resource access, where dominant males often have more offspring in a particular period (Alberts, 2012) and dominant females have a higher lifetime reproductive output (van Noordwijk and van Schaik, 1999; Pusey, 2012). Thus, aggression leads to individual fitness (Darwin, 1859) and aggressive behaviour is considered a straightforward method to access resources and is often implied when investigating resource access.

Dominance can also be used to coerce individuals. Coercion in a sexual context has been described for chimpanzees (Pan troglodytes: Smuts and Smuts, 1993; Muller et al., 2011; Feldblum et al., 2014) and orang-utans (Pongo pygmaeus: Knott et al., 2010), where males can force a female to mate. However, systematic coercion of group members is in general not effective (CluttonBrock, 2002). Accordingly, forcing cooperation or grooming it is typically not successful (Overduin-de Vries et al., 2020), since the partner can withhold support or grooming. This leverage of cooperation partners (Lewis, 2002, 2018) or of individuals with specific competences (Chapais, 2015) requires other social strategies than aggression and dominance (Watts, 2010).

\section{Human Children}

Although aggression is often viewed by peer relation researchers as pathological, recent developments acknowledge that aggression can be functional for resource access (Pellegrini, 2008). An important difference in this regard is between reactive and proactive aggression. Reactive aggression is a reaction to a (presumed) threat that is associated with anger and emotion dysregulation. The function of this kind of behaviour is to defend oneself, not to access resources at the expense of others. Proactive or instrumental aggression is planned, goal-oriented, and unemotional. The function of this type of aggression is to take possession of things or to dominate or intimidate (Polman et al., 2009) and is positively associated with high rank (Stolz et al., 2016; van den Berg et al., 2019). For example, adolescents use aggression against same-sex peers (i.e., competitors) in order to obtain contacts with the other sex (Pellegrini, 2008).

A theory on the strategic use of behaviour is Resource Control Theory (RCT) of Hawley (1999). In this theory, coercive resource control strategies refer to proactive (instrumental) aggression (e.g., taking, demanding, threatening, and commanding). They appear early in life: toddlers and pre-schoolers predominantly apply aggressive strategies to obtain resources. Several studies have shown that applying aggression in terms of RCT's coercive strategies is effective for obtaining above average resource access, both in preschool, childhood, and adolescence (Hawley, 2007, 2014, 2015; Reijntjes et al., 2018;
Vermande et al., 2018). This also holds for bullying, a specific subtype of proactive aggression that is increasingly conceptualized as strategic behaviour motivated by a desire to gain a high position and resource access in the peer group (Olthof et al., 2011; Reijntjes et al., 2013a; Lee, 2020). Bully-victim relations resemble dominance-relations in that there is a power difference between perpetrator and victim.

\section{Conclusion and Comparison}

In primatology, aggressive conflicts and dominance relations are ways to exclude others from scarce resources. Developmental scientists stress that not all highly aggressive children have resource access. The type of aggression matters: resource access is positively associated with instrumental (proactive) rather than reactive aggression. In primatology, the accessed resources are typically identified, such as food and mating partners and one study mentions a support, while in developmental psychology what constitutes these resources is often more implicit or general. However, aggression may often not be effective in accessing social resources (see section Multidimensional Concepts of Social Asymmetry).

\section{Affiliative Behaviour}

Affiliative behaviour binds individuals in groups (see section Aggressive, Affiliative, and Action Indicating Behaviours may Provide Access to Resources) and is related to social proximity and cohesion (Silk, 2002; Pellegrini, 2008). Like aggression, affiliative behaviour has been linked to resource access.

\section{Primates}

In primates, affiliation encompasses behaviours such as proximity, play, food-sharing, and huddling (Sussman et al., 2005; Wooddell et al., 2019), yet grooming is the most prevalent (Sussman et al., 2005) and will be the focus behaviour here.

The value of grooming has long been acknowledged, since it may be directed at valuable partners that can provide agonistic support (i.e., to form a coalition) during a conflict (Kummer, 1978). Note that in this scenario primates exchange one resource (support) for another (winning a conflict, obtaining a high rank or accessing a mating partner). In species with a despotic dominance hierarchy grooming is preferentially directed at higher-ranking individuals to secure their coalitionary support (Seyfarth, 1977; Schino, 2001), while grooming is not related to rank differences in species with an egalitarian dominance hierarchy (Leinfelder et al., 2001). This indicates that bonds can affect dominance relationships and that these may be correlated. However, aggressive and affiliative behaviour can independently lead to resource access (Overduin-de Vries et al., 2020). Similarly, personality research indicates that the expression of aggressive and affiliative behaviour load on different axes and may be independent (Koski, 2011; Seyfarth et al., 2012; Wooddell et al., 2017; Ebenau et al., 2020).

Grooming can be used to obtain direct access to a resource. The value of grooming as a commodity to obtain direct benefits has been theoretically deduced in Biological Market 
Theory (BMT; Noë et al., 1991; Noë and Hammerstein, 1994). The distribution of grooming among group members will depend on the value of the resource that others have to offer and on the number of other individuals that offer this resource. An individual that has leveraged since it can provide a rare commodity (e.g., the only individual that can open a box with food; Fruteau et al., 2009) has a higher value than when more individuals can provide access. Therefore, the provider of the rare commodity can demand a higher payment for this commodity, for example, longer grooming. Accordingly, an individual with leverage over a relatively rare resource (e.g., grooming: Schino and Aureli, 2009, food: Fruteau et al., 2009, and infants: Henzi and Barrett, 2002) can obtain more grooming. BMT is often considered to explain short-term exchanges of grooming and resource access (Henzi and Barrett, 2007).

Systematic grooming of particular individuals will lead to bonds (Silk, 2002; Massen et al., 2010; Seyfarth and Cheney, 2012; Evers et al., 2014, 2015). Although the existence of bonds has long been acknowledged (e.g., Kummer, 1978; Wrangham, 1980), only the last 15 years evidence emerged that bonds provide fitness benefits (Nishida and Hosaka, 1996; Palombit et al., 1997; Silk et al., 2006a,b; Kulik et al., 2012; Massen et al., 2012). The proximate mechanisms responsible for these benefits are often not addressed (Thompson, 2019). For females these mechanisms may concern the proximity patterns and ensuing safety, for males enhanced interest from mating partners.

Affiliative behaviour may also repair the harmful effects of aggression. de Waal and van Roosmalen (1979) were the first to notice that chimpanzees do not necessarily keep distance after a conflict, but that the former opponents can affiliate with each other. They proposed that this constituted reconciliation. Reconciliation has been found in numerous other primates and animals (Aureli and de Waal, 2000) and functions to reduce stress, prevent renewed aggression, and repair the relationship (Aureli et al., 2002). Reconciliation is especially found among family members and among individuals with bonds (Aureli et al., 2002).

Effects of bonds have been found, while controlling for dominance (e.g., Silk et al., 2006a, 2010), indicating that affiliative strategies cannot be explained solely on the basis of dominance and that these two social strategies have separate effects. However, dominance may overshadow bonds, since in particular settings dominance may be more important (Fruteau et al., 2009; Massen et al., 2011), suggesting that a bond concerns the voluntary bestowing of benefits. The settings where bonds are or are not expressed have not been addressed systematically, but dominance may overrule good relationships in particular in situations of high contest competition. This suggests that contest for a resource should not be high, but possibly intermediate or low, for bonds to have effect. In addition, there is ample evidence that bonds lead to cooperative coalitions (Schino, 2007; Schino et al., 2007), suggesting that bonds provide benefits in contest competition for monopolisable but shareable resources. Altogether, this suggests that aggressive and affiliative strategies may be correlated, but also may operate independently (Wooddell et al., 2017).

\section{Human Children}

In developmental psychology, aggression and affiliative behaviour have traditionally been placed at opposite ends of a continuum (Hawley et al., 2007a; Pellegrini, 2008). More recently, however, it has been acknowledged that aggression and affiliation may share the same function (i.e., gaining resources; Table 1).

In line with primatologists, traditionally most scholars defined dominance in terms of aggression and power-submission relations. However, in the 1970s and 1980s some human ethologists - inspired by personal observations, evolutionary theory (e.g., Trivers, 1971), and social exchange theories suggested that cooperative behaviours may also contribute to establishing dominance (e.g., Crook, 1971; Strayer and Strayer, 1976; Charlesworth, 1988). ${ }^{1}$ For example, it was observed that a relatively low-aggressive preschool girl was the most high-ranking individual in the group, suggesting that cooperative interactions play a role in young children's hierarchical relations (Strayer and Strayer, 1976, p. 987-988). This possibility was investigated with respect to level of resource utilization in young children (i.e., watching a movie through a movie viewer). It was shown that cooperation can function as competition over limited resources (Charlesworth, 1982, 1988, 1996), next to being aggressive. Young children who combined cooperation with coercion were most effective in achieving viewing time (e.g., Charlesworth and Dzur, 1987; Charlesworth, 1996; Green et al., 2003; Table 1).

Some scholars posit that at the beginning of a new group, individuals predominantly resort to aggression to establish resource control, but over time engage in lower levels of aggression and increase their use of prosocial behaviour to maintain it (Pellegrini, 2008; Pellegrini et al., 2011). Partial support has been found for this hypothesis. For example, in a study across the school year, pre-schoolers' aggressive behaviour decreased over time, but positive interactions remained relatively high in pre-schoolers scoring high on resource control. A noticeable example of positive interactions concerned reconciliation: pre-schoolers high on resource control were more likely to initiate reconciliation after also initiating an aggressive conflict: they appeared to reconcile strategically as a way to keeping defeated peers as affiliates (or simply to prevent that defeated peers would defame them to others; Roseth et al., 2011). In another study, other aspects of prosocial behaviour (e.g., sharing, helping) predicted an increase in teacher-rated resource control after 4 months in early childhood (Ostrov and Guzzo, 2015). Unfortunately, this study did not control for the effect of aggression. Contrary to Pellegrini's hypothesis, resource control was not a predictor of changes (i.e., increase) in prosocial behaviour over time (Ostrov and Guzzo, 2015).

${ }^{1}$ The strategic use of aggression and cooperation shares features with social exchange theories which posit that social behaviour is driven by subjective cost-benefit analysis and the comparison of alternatives (Green and Rechis, 2006). However, social exchange theories do not have aggression and cooperation for resources as a central theme (Charlesworth, 1996) 
According to RCT, two broad classes of strategic behaviours to acquire resources can be distinguished (Table 1): coercive (section Aggressive Behaviour) and prosocial resource control strategies. Prosocial strategies appear around the age of five, as verbal abilities and social skills to negotiate with peers develop (Hawley, 1999). Prosocial strategies pertain to positive, socially acceptable behaviours used to obtain resource control, including promising reciprocity and cooperation (e.g., trading toys, promising friendship, and helping someone who does not need help). It should be noted that according to RCT, prosocial strategies are self-serving rather than other-serving or altruistic (Hawley, 2014, 2015). They are instrumental (Hawley and Bowers, 2018) and could be described as "positively assertive" (Vermande et al., 2018). Nevertheless, prosocial strategies are supposed to shape bonds with others. Using various methods and age groups (e.g., observations of dyads competing for a novel toy; rating scales with different informants), coercive and prosocial strategies vary from being mildly to strongly positively correlated. Negative correlations between the two types of strategies were never found, suggesting a common function (i.e., obtaining resources; Hawley, 2007; Hawley and Bowers, 2018). In addition, both coercive and prosocial resource control strategies are effective for obtaining above average resource control (Hawley, 2007; Hawley and Bowers, 2018). However, in spite of being correlated, others have found that the direct effect of prosocial strategies compared to coercive strategies is small in children and adolescents (Bassa, 2018; Vermande et al., 2018). Coercive and prosocial strategies may interact, explaining additional variance (Bassa, 2018).

RCT classifies participants into five different subtypes typically using a priori cut-off points (Hawley and Bowers, 2018). Prosocial controllers primarily use prosocial strategies, coercive controllers primarily use coercive strategies, bistrategic controllers score high on both, noncontrollers score low on both, and the remaining typicals score neither low nor high on both strategies. These subtypes show longitudinal stability from grade 4 to 6 (Reijntjes et al., 2018). Bistrategic controllers across all age groups are the most successful in acquiring resources, followed by prosocial and coercive controllers, whereas typicals and noncontrollers have only average and negligible/low levels of resource control, respectively (Hawley, 2014, 2015). However, some studies showed bistrategics to score as high on resource control as prosocial controllers (Hawley, 2003) or coercive controllers (Reijntjes et al., 2018), and prosocials and typicals do not always differ in resource control (Olthof et al., 2011; Reijntjes et al., 2018). In addition, bistrategics, like prosocial controllers, are sought out for friendships and are liked by peers (Hawley and Bowers, 2018), but others found that they evoked clear negative peer reactions (e.g., enmity nominations, low likeability; Reijntjes et al., 2018).

To what extent prosocial behaviour and instrumental prosocial resource control strategies overlap, is not clear and need further scrutiny (Ostrov and Guzzo, 2015). In addition, correlations between aggressive and affiliative behaviour may be lower if the items do not cover instrumentality, but only refer to the form of the behaviour.

\section{Conclusion and Comparison}

In both primate and human studies, affiliative behaviour can lead to resource access. While in primate studies affiliative relationships are determined independently of dominance and in human studies they are traditionally considered opposite ends of a continuum, both fields recently acknowledged that both may be correlated. Nevertheless, in primatology aggression and affiliation are usually studied in isolation, except the special case of studies concerning reconciliation, whereas in developmental psychology often both types of behaviours and their relative importance are examined. Results show that the combined use of aggression and affiliation by one individual may enhance resource access. A person-centred approach is unfamiliar in primatology. However, the two fields differ in identifying the accessed resources. In primatology, empirical outcomes indicate that affiliative behaviours can lead in several ways to resource access: they can access services, such as coalitionary support, and these services can affect relationships, such as enhance dominance, and services can lead to or be exchanged for resources, such as food or mating partners. These are often, but not necessarily, social resources. Although in developmental psychology some studies measured access to specific resources (e.g., a toy and a movie viewer), often a measure of a child's general resource access effectiveness (resource control) is used.

\section{Action Indicating Behaviour: Inspiring Followers to Follow the Lead}

Action indicating behaviour refers to inspiring followers to conduct particular behaviour that the leading individual wants. It is probably based on reputation, prestige, or peer regard (Vermande et al., 2018). Action indicating behaviour and its connection with resource access has received little explicit attention, but was recently explored in children (Vermande et al., 2018). In primates, the role of this behaviour has not been specifically addressed, but there are related studies on leadership and prestige (Chapais, 2015; Smith et al., 2016). Therefore, we start this section with human children and then discuss primates. There are some first indications that action indicating behaviour may lead to resource access.

\section{Human Children}

Action indicating behaviour involves inspiring others to follow one's example (e.g., by social learning or modelling; Henrich and Gil-White, 2001) or intentions (e.g., a common goal, joint actions) because of the promise of success. This behaviour has been theoretically linked to leadership in organizations (Judge et al., 2009; Hogan and Blickle, 2018). As leadership is a measure of social asymmetry (see section Multidimensional Concepts of Social Asymmetry), action indicating behaviour may also be associated with resource access. That is, children who are able to indicate action for group members may be more proficient in getting what they want.

Vermande et al. (2018) examined the degree to which action indicating behaviour, referred to as "inspirational behaviour," was associated with resource control above and beyond the 
effects of RCT's (see sections Aggressive Behaviour and Affiliative Behaviour) coercive and prosocial strategies in young adolescents. They used peer ratings of strategy use and resource control. The action indicating behaviour items related to trying to get others enthusiastic about something, convincing others, and persuading others by giving suggestions. Confirmatory factor analyses indicated that the prosocial and action indicating strategy items, which refer both to socially accepted behaviour, loaded strongly on their own unique factor, and thus are different dimensions. All three classes of social behaviour were positively correlated with each other and with resource control, supporting the view that the three behaviours share a common underlying function. In addition, all three classes of behaviours were positive statistical predictors of resource control, but both coercive and action indicating behaviour were moderately strong predictors, whereas prosocial strategy use was a relatively weak predictor of resource control. Adolescents with prestige may be especially adept in using action indicating behaviour effectively (Vermande et al., 2018).

\section{Primates}

Several lines of research suggest that primates may show action indicating behaviour as well. Firstly, the related concept of prestige (excellence or competence in valued domains; see section Multidimensional Concepts of Social Asymmetry) has also been linked to dominance in primates and the social learning processes involved in prestige (i.e., followers copying the behaviour of expert role models) may also be relevant in primates (Chapais, 2015). In addition, the concept of travel leadership has been amply studied in primates (Smith et al., 2016) and may be related to action indicating behaviour. Moreover, the concept of "reputation," that follows from the theory of indirect reciprocity, where a beneficial act to one individual results in a beneficial act to the original benefactor by a non-involved individual (Nowak and Sigmund, 1998), may apply. Thus, we will explore the link between action indicating behaviour, competences, social learning, travel order, and reputation.

Chapais (2015) reacted on the claim that only humans have status based on dominance and prestige (Henrich and Gil-White, 2001) by substantiating that also primates can exert these two routes to achieve status (see section Multidimensional Concepts of Social Asymmetry). However, in primates these prestigerelated competences are derived from or correlated with coercive dominance. They have become independent only in humans, since human cumulative culture has led to many domains of non-competitive competences (e.g., making tools, dealing with the supra-natural, and dancing). Nevertheless, he argued that these two classes of social behaviour both lead to status and that also in primates action indicating behaviour is related to resource access. How these two types of behaviour relate to one another, whether they are indeed always closely linked or can be independent, has to be further explored. Moreover, the benefits of competence-based dominance remain to be established.

As action indicating behaviour or prestige incites others to follow example, studies on social learning may be informative. In these studies, a demonstrator shows a behaviour and followers may copy it. Demonstrators that are dominant (Horner et al., 2010; but see Botting et al., 2018), familiar (Perry, 2011), more knowledgeable (van de Waal et al., 2010) or obtain more benefits (Bono et al., 2018) are more readily copied. Knowledge of a demonstrator's abilities results from the observation of their earlier performance, i.e., its reputation that may not affect the observer directly. Therefore, a demonstrator's behaviour and its effect on the observer can highlight processes involved in indirect reciprocity. In addition, the characteristics of copied demonstrators may inform us on the competences that primates express (cf. Chapais, 2015) and that lead to following. While apes can observe the reputation of others (Herrmann et al., 2013), they may not manage their own reputation (Engelmann et al., 2016). One benefit for demonstrators has been found: being knowledgeable may lead to obtaining bonds independent of dominance (ring-tailed lemurs: Lemur catta; Kulahci et al., 2018).

Leadership in primate travel orders (Petit and Bon, 2010; King and Sueur, 2011) may be viewed as a specific example of indicating action to group members. Travel orders may be started by dominants or may be distributed over multiple group members (review: King and Sueur, 2011). However, coercive dominance will not be required in inciting group travel, since typically others will follow the "lead" of an individual without this leader forcing or enticing followers (Conradt and Roper, 2005). Therefore, leadership is potentially independent from aggressive and affiliative social behaviours. Indeed, followers follow not only dominants (Watts, 2000; Rowe et al., 2018), or kin (Leca et al., 2003; Rowe et al., 2018) and close affiliates (Wang et al., 2016), but also central group members (Leca et al., 2003). The ecological setting may also determine who is leading the travel order: when food sources are monopolisable dominants lead, while leadership is distributed with non-monopolizable food sources (King et al., 2008). The leader may obtain most benefits through enhanced access to food (King et al., 2008) or may not directly benefit from its behaviour (Smith et al., 2016). The benefits for followers may concern group cohesion. Altogether, whether travel leadership benefits the participants, either leader or follower, has received only limited attention. In addition, the individual competences of leaders (cf. Chapais, 2015) should be determined. In any case, also in primates action indicating behaviour in the form of travel order leadership may be different from aggression and affiliation.

\section{Conclusion and Comparison}

Action indicating behaviour appears to be a third way to access resources in young human adolescents, above and beyond aggressive and affiliative behaviour. Others may follow inspirational individuals due to their competences (prestige), yet what constitutes competences needs systematic attention. Primate literature on the topics of prestige, leadership, and social learning suggests that action indicating behaviour may gain specific resources, such as preferred food or obtaining bonds. In the study with human adolescents, resource access was measured as general resource control. Altogether, action indicating behaviour as a means to gain resource access is relatively new and has been little investigated. 


\section{DISCUSSION}

This conceptual analysis highlighted that resource access can conceptually be linked to three different classes of social behaviour (research question 1; Figure 1) and explored empirical evidence that actually links these classes of social behaviour to resource access (research question 2), what resources are accessed (research question 3) and how these different classes of social behaviour are related (research question 4).

\section{Three Classes of Social Behaviours Are Empirically Linked to Resource Access}

Empirical studies on the link between resource access and the three classes of social behaviour show that the contribution of aggression and affiliation to resource access has been widely documented (research question 2). However, in primatology, aggression and affiliation are usually studied in isolation except the special case of studies concerning reconciliation whereas in developmental psychology often both types of behaviours and their relative importance are examined. Results show that the combined use of aggression and affiliation may enhance resource access.

As yet only initial empirical support exists for the link between action indicating behaviour and resource access. Its contribution to resource control in human children has been found in one study showing that inspiring others is indeed a separate dimension, that it is correlated to both aggressive and affiliative behaviour, and that it explains a significant portion of variance in resource control above and beyond aggressive and affiliative behaviour (section Action Indicating Behaviour: Inspiring Followers to Follow the Lead). These results require further support. In addition, what makes a child inspiring to followers should be investigated. Prestige (i.e., competence in a valued domain) may be relevant. In primates, the relation between action indicating behaviour and resource access is implicit in several studies concerning prestige, social learning, and travel order and needs to be further explored. Research is also needed to understand the temporal relations between social behaviours and resource access, for example, to investigate how effective resource access leads to the use of more action indicating behaviour and receiving more affiliative offers from interaction partners over time.

\section{The Classes of Social Behaviours and Specific Types of Resources}

The three classes of social behaviours may access different types of resources (research question 3). In developmental psychology, the nature of the accessed resources is typically less clear than in primatology. This difference is due to the different methods: while primatology has to employ observational methods, in developmental psychology often questionnaires are used that do not necessarily specify resources or combine them in an umbrella term like "resource control." We cautiously suggested (Figure 1) that different classes of social behaviour may be employed to access different types of resources. Although primate literature indicates that specific behaviour may lead to specific resources (i.e., aggressive behaviour provides access to food, while affiliative behaviour provides access to social resources), also different connections are found. Both aggression and affiliation can provide access to mating partners, aggression results in excluding competitors for a mating partner and forcing of a mating partner, whereas affiliation may serve to overcome leverage from the mating partner. Also support, a social resource that is often obtained through grooming but can also be required through aggression, can lead to access to food, defending a territory and mating partners. Thus, access to resources can be a direct consequence of social behaviour, or one type of resource can be exchanged for another (indirect) and such exchanges of resources may even happen several times (grooming for support for dominance for access to food). In short, the link between a class of social behaviour and type of resource accessed appears to be variable and may be indirect. The connection between social behaviour and type of resource has received little attention in developmental psychology, although Pellegrini (2008) argues that in scramble situations, characterised by relatively abundant resources, individuals are less likely to use aggression than affiliation. However, systematic exploration of the connection between class of social behaviour and resource type, and whether indicting action leads to access of even different resources (e.g., joint actions that the leader wants or pursuits), has to be conducted. Both the typical connection between a class of social behaviour with a type of resource and the use of alternative social behaviours to access similar resources, indicate that the ability of an individual to show all these behavioural alternatives, i.e., social complexity, will provide benefits.

\section{Combination of the Classes of Social Behaviours}

The three classes of social behaviours can be related in different ways: diametric opposites (negatively correlated), independent (not correlated), or co-expressed (positively correlated; research question 4). As described in section Three Classes of Social Behaviour and Resource Access: Empirical Links, several studies show that aggression and affiliation (and one study that aggression, affiliation and action indicating behaviour) positively correlate, whereas others indicate that they are independent. We found no studies suggesting that the behavioural dimensions are opposites.

With the exception of reconciliation, in primatology aggression and affiliation are usually studied in isolation or when controlling for dominance, whereas in developmental psychology often several types of behaviours and their relative importance are examined (section Three Classes of Social Behaviour and Resource Access: Empirical Links). This may be done using a variable-centred approach, including investigating children's social behaviours as predictors of resource control. Another way to study the effects of social behaviours is to distinguish subtypes or groups of children, where an individual is characterised based on the relative use of one or more types of behaviours. This person-centred approach has been examined with aggressive and affiliative behaviour; combinations with action indicating behaviour are yet to be explored. Results typically show that children who combine aggression and affiliation (i.e., "bistrategic controllers") are particularly effective resource controllers (see the RCT in section Affiliative Behaviour). However, whether this superiority 
in resource control is associated with other benefits such as psychosocial health is not clear. For example, bistrategic adolescents have been found to display lower than average levels of self-esteem and mental health over time (Ciarrochi et al., 2019) and noncontrolling children, although the lowest on resource control, do not always experience negative evaluations by peers (Reijntjes et al., 2018). A person-oriented approach is relatively new in primate research and may yield interesting insights.

Several scholars suggest social competence as a central concept in integrating the different classes of social behaviour (e.g., Strayer, 1989; Hawley, 2007; Vaughn and Santos, 2009). Some primate studies indicate that specific individuals may be able to use both aggressive and affiliative behaviour to access resources (e.g., Overduin-de Vries et al., 2020). In human children, effective resource access may be attributed to the flexible, strategic combination of social behaviours in different competitive contexts and/or with different interaction partners (Hawley, 1999; Pellegrini et al., 2011). Children high on resource control are assumed to have sophisticated social-cognitive skills that allow them to execute social behaviours successfully (Hawley et al., 2007a,b; Vermande et al., 2018). These skills may include abilities in the cognitive processing of emotions and the interpersonal regulation of emotion as recent studies suggest (Engel-Yeger et al., 2016; De Berardis et al., 2017). However, most studies rather focus on indicators of social competence (e.g., the combination of high status and good peer relations). Exactly what skills are involved has been rarely examined.

\section{Implications for Education}

Several implications and issues emerge from the above discussion. First, school policy should not only emphasize academic performance, but also focus on socialisation opportunities that are necessary for the development of social competence (Liu et al., in press). These include offering non-academic classes (e.g., drama, music, and art; Stump et al., 2009), using collaborative learning techniques (Laal and Ghodsi, 2012), and encouraging pupils to experience leadership roles (Karagianni and Montgomery, 2018). Second, teachers have the difficult task of protecting the interests of both individual children and their peers. On the one hand, as aggression can be functional and may not be harmful to the social well-being of the child (section Affiliative Behaviour), the question is whether teachers should strive to root out all aggression in all children (Stump et al., 2009). On the other hand, bullying a specific subtype of aggression should not be tolerated. Because bullying is an effective way to gain resource access and popularity in the

\section{REFERENCES}

Alberts, S. C. (2012). "Magnitude and sources of variation in male reproductive performance" in The evolution of primate societies. eds. J. C. Mitani, J. Call, P. M. Kappeler, R. A. Palombit and J. B. Silk (Chicago: The University of Chicago Press), 412-431.

Anderson, C. A., and Bushman, B. J. (2002). Human aggression. Annu. Rev. Psychol. 53, 27-51. doi: 10.1146/annurev.psych.53.100901.135231

Arseneau-Robar, T. J. M., Taucher, A. L., Müller, E., van Schaik, C., Bshary, R., and Willems, E. P. (2016). Female monkeys use both the carrot and the peer group (section Aggressive Behaviour) with little personal costs (Reijntjes et al., 2013b), bullies are likely to have little motivation to change their behaviour. Hence, intervention is most likely to be effective when bullying becomes less rewarding (e.g., fostering anti-bullying attitudes in the peer group, Polanin et al., 2012) and bullies are taught more acceptable ways to achieve resource access and popularity (Ellis et al., 2016). At the same time, offering children safe strategies to standing up for victims as well as teacher intervention in stopping bullying incidents and supporting the victim are important (Salmivalli et al., 2010; Swift et al., 2017). At a more general level, teachers should help children who are permanent losers of resource competition (e.g., by fostering social skills). Intervening by teachers starts with teachers being able to recognize the dynamics of competition for resources within classrooms.

\section{CONCLUSION}

There are theoretical and empirical arguments for three classes of social behaviour being involved in having access to resources. Empirical support for action indicating behaviour is limited, however. Future studies should address the (in)dependency of the behavioural dimensions, their relative importance, individual differences in combined expression and their specific benefits. The ability to use all three classes of behaviour, and thus social complexity, appears to be highly beneficial. Altogether, social behaviour and its link to resource access seem to be alike in primates and human children, and differences between the research fields identified novel avenues of research.

\section{AUTHOR CONTRIBUTIONS}

Both authors listed have made a substantial, direct and intellectual contribution to the work, and approved it for publication. The authors share first authorship.

\section{FUNDING}

The research was funded by seed money from the Utrecht University Strategic Theme Dynamics of Youth SM.YI.2013.11. GS to A. H. A. Reijntjes, ES, MV, and H. de Vries and by Netherlands Organization for Scientific Research (NWO), Research Area Social Sciences, No. 431-14-008 to MV. 
of coercive and prosocial strategies on resource control). master's thesis. Utrecht, Netherlands: Utrecht University.

Bono, A. E. J., Whiten, A., van Schaik, C., Krützen, M., Eichenberger, F., Schnider, A., et al. (2018). Payoff- and sex-biased social learning interact in a wild primate population. Curr. Biol. 28, 2800-2805. doi: 10.1016/j. cub.2018.06.015

Botting, J., Whiten, A., Grampp, M., and van de Waal, E. (2018). Field experiments with wild primates reveal no consistent dominance-based bias in social learning. Anim. Behav. 136, 1-12. doi: 10.1016/j.anbehav.2017.11.025

Chapais, B. (2015). Competence and the evolutionary origins of status and power in humans. Hum. Nat. 26, 161-183. doi: 10.1007/s12110-015-9227-6

Charlesworth, W. R. (1982). The ontogeny of political behavior: an approach to research. Am. Behav. Sci. 25, 273-293.

Charlesworth, W. R. (1988). "Resources and resource acquisition during ontogeny" in Sociobiological perspectives on human development. ed. K. B. M. Donald (New York, NY: Springer), 24-77.

Charlesworth, W. R. (1996). Co-operation and competition: contributions to an evolutionary and developmental model. Int. J. Behav. Dev. 19, 25-38. doi: $10.1177 / 016502549601900103$

Charlesworth, W. R., and Dzur, C. (1987). Gender comparisons of preschoolers' behavior and resource utilization in group problem solving. Child Dev. 58, 191-200.

Cheng, J. T. (2020). Dominance, prestige, and the role of levelling in human social hierarchy and equality. Curr. Opin. Psychol. 33, 238-244. doi: 10.1016/j. copsyc.2019.10.004

Ciarrochi, J., Sahdra, B. K., Hawley, P. H., and Devine, E. K. (2019). The upsides and downsides of the dark side: a longitudinal study into the role of prosocial and antisocial strategies in close friendship formation. Front. Psychol. 10:114. doi: 10.3389/fpsyg.2019.00114

Cillessen, A. H. N. (2011). "Toward a theory of popularity" in Popularity in the peer system. eds. A. H. N. Cillessen, D. Schwartz and L. Mayeux (New York, NY: Guilford), 273-299.

Cillessen, A. H. N., and Marks, P. E. L. (2011). "Conceptualizing and measuring popularity" in Popularity in the peer system. eds. A. H. N. Cillessen, D. Schwartz and L. Mayeux (New York, NY: Guilford), 25-56.

Clutton-Brock, T. (2002). Breeding together: kin selection and mutualism in cooperative vertebrates. Science 296, 69-72. doi: 10.1126/science.296.5565.69

Conradt, L., and Roper, T. J. (2005). Group decision-making in animals. Nature 421, 155-158. doi: 10.1038/nature01294

Cook, J. L., Den Ouden, H. E. M., Heyes, C. M., and Cools, R. (2014). The social dominance paradox. Curr. Biol. 24, 2812-2816. doi: 10.1016/j. cub.2014.10.014

Crook, J. H. (1971). "Sources of cooperation in animals and man" in Man and beast: Comparative social behavior. eds. J. F. Eisenberg and W. S. Dillon (Washington, DC: Smithsonian Institution Press), 236-260.

Darwin, R. (1859). On the origin of species. London: Murray.

De Berardis, D., Fornaro, M., Orsolini, L., Valchera, A., Carano, A., Vellante, F., et al. (2017). Alexithymia and suicide risk in psychiatric disorders: a minireview. Front. Psychiatry 8:148. doi: 10.3389/fpsyt.2017.00148

de Waal, F. B. M., and Luttrell, L. M. (1988). Mechanisms of social reciprocity in three primate species: symmetrical relationship characteristics or cognition? Ethol. Sociobiol. 9, 101-118. doi: 10.1016/0162-3095(88)90016-7

de Waal, F. B. M., and van Roosmalen, A. (1979). Reconciliation and consolation among chimpanzees. Behav. Ecol. Sociobiol. 5, 55-66. doi: 10.1007/BF00 302695

Ebenau, A., von Borell, C., Penke, L., Ostner, J., and Schülke, O. (2020). Integrative personality assessent in wild Assamese macaques (Macaca assamensis). J. Comp. Psychol. 134, 27-41. doi: 10.1037/com0000190

Eisenberg, N., Eggum, N. D., and Di Giunta, L. (2010). Empathy-related responding: associations with prosocial behavior, aggression, and intergroup relations. Soc. Issues Policy Rev. 4, 143-180. doi: 10.1111/j.1751-2409. 2010.01020.x

Ellis, B. J., Volk, A., Gonzalez, J. -M., and Embry, D. (2016). The meaningful roles intervention: an evolutionary approach to reducing bullying and increasing prosocial behavior. J. Res. Adolesc. 26, 622-637. doi: 10.1111/ jora. 12243

Engelmann, J. M., Herrmann, E., and Tomasello, M. (2016). The effects of being watched on resource acquisition in chimpanzees and human children. Anim. Cogn. 19, 147-151. doi: 10.1007/s10071-015-0920-y
Engel-Yeger, B., Muzio, C., Rinosi, G., Solano, P., Geoffroy, P. A., Pompili, M., et al. (2016). Extreme sensory processing patterns and their relation with clinical conditions among individuals with major affective disorders. Psychiatry Res. 236, 112-118. doi: 10.1016/j.psychres.2015.12.022

Evers, E., De Vries, H., Spruijt, B. M., and Sterck, E. H. M. (2014). The EMO-model: an agent-based model of primate social behavior regulated by two emotional dimensions, anxiety-FEAR and satisfaction-LIKE. PLoS One 9:e87955. doi: 10.1371/journal.pone.0087955

Evers, E., De Vries, H., Spruijt, B. M., and Sterck, E. H. M. (2015). Emotional bookkeeping and high partner selectivity are necessary for the emergence of partner-specific reciprocal affiliation in an agent-based model of primate groups. PLoS One 10,1-33. doi: 10.1371/journal.pone.0118921

Farmer, T. W., and Rodkin, P. C. (1996). Antisocial and prosocial correlates of classroom social positions: the social network centrality perspective. Soc. Dev. 5, 174-188.

Feldblum, J. T., Wroblewski, E. E., Rudicell, R. S., Hahn, B. H., Paiva, T., Cetinkaya-Rundel, M., et al. (2014). Sexually coercive male chimpanzees sire more offspring. Curr. Biol. 24, 2855-2860. doi: 10.1016/j.cub.2014.10.039

Fragale, A. R., Overbeck, J. R., and Neale, M. A. (2011). Resources versus respect: social judgments based on targets' power and status positions. J. Exp. Psychol. 47, 767-775. doi: 10.1016/j.jesp.2011.03.006

Fruteau, C., Voelkl, B., Damme, E.Van, and Noë, R. (2009). Supply and demand determine the market value of food providers in wild vervet monkeys. Proc. Natl. Acad. Sci. U. S. A. 106, 12007-12012. doi: 10.1073/pnas.0812280106

Gest, S. D., Graham-Bermann, S. A., and Hartup, W. W. (2001). Peer experience: common and unique features of number of friendships, social network centrality, and sociometric status. Soc. Dev. 10, 23-40. doi: 10.1111/14679507.00146

Giordano, P. C., Longmore, M. A., and Manning, W. D. (2006). Gender and the meanings of adolescent romantic relationships: a focus on boys. Am. Sociol. Rev. 7, 260-287. doi: 10.1177/000312240607100205

Green, V. A., Cillessen, A. H. N., Berthelsen, D., Irving, K., and Catherwood, D. (2003). The effect of gender context on children's social behavior in a limited resource situation: an observational study. Soc. Dev. 12, 587-603.

Green, V. A., and Rechis, R. (2006). Children's cooperative and competitive interactions in limited resource situations: a literature review. J. Appl. Dev. Psychol. 27, 42-59. doi: 10.1016/j.appdev.2005.12.002

Hamilton, W. D. (1964). The genetical theory of social behaviour I, II. J. Theor. Biol. 7, 1-52.

Hawley, P. H. (1999). The ontogenesis of social dominance: a strategy-based evolutionary perspective. Dev. Rev. 19, 97-132. doi: 10.1006/drev.1998.0470

Hawley, P. H. (2003). Prosocial and coercive configurations of resource control in early adolescence: a case for the well-adapted Machiavellian. MerrillPalmer Q. 49, 273-309. doi: 10.1353/mpq.2003.0013

Hawley, P. H. (2007). "Social dominance in childhood and adolescence: why social competence and aggression may go hand in hand" in Aggression and adaptation: The bright side to bad behavior. eds. P. H. Hawley, T. D. Little and P. C. Rodkin (Mahwah, NJ: Erlbaum), 1-30.

Hawley, P. H. (2014). The duality of human nature: coercion and prosociality in youths' hierarchy ascension and social success. Curr. Dir. Psychol. Sci. 23, 433-438. doi: 10.1177/0963721414548417

Hawley, P. H. (2015). Social dominance in childhood and its evolutionary underpinnings: why it matters and what we can do. Pediatrics 135 (Suppl. 2), S31-S38. doi: 10.1542/peds.2014-3549D

Hawley, P. H., and Bowers, A. R. (2018). "Evolution and peer relations. Considering the functional roles of aggression and prosociality" in Handbook of peer interactions, relationships, and groups. 2nd Edn. eds. W. H. Bukowski, B. Laursen and K. H. Rubin (New York, NY: Guilford), 106-122.

Hawley, P. H., Johnson, S. E., Mize, J. A., and McNamara, K. A. (2007a). Physical attractiveness in preschoolers: relationships with power, status, aggression and social skills. J. Sch. Psychol. 45, 499-521. doi: 10.1016/j.jsp.2007.04.001

Hawley, P. H., Little, T. D., and Card, N. A. (2007b). The allure of a mean friend: relationship quality and processes of aggressive adolescents with prosocial skills. Int. J. Behav. Dev. 31, 170-180. doi: 10.1177/0165025407074630

Henrich, J., and Gil-White, F. J. (2001). The evolution of prestige. Freely conferred deference as a mechanism for enhancing the benefits of cultural transmission. Evol. Hum. Behav. 22, 165-196. doi: 10.1016/s1090-5138(00)00071-4

Henzi, S. P., and Barrett, L. (2002). Infants as a commodity in a baboon market. Anim. Behav. 63, 915-921. doi: 10.1006/anbe.2001.1986 
Henzi, S. P., and Barrett, L. (2007). Coexistence in female-bonded primate groups. Adv. Study Behav. 37, 43-81. doi: 10.1016/S0065-3454(07)37002-2

Herrmann, E., Keupp, S., Hare, B., Vaisj, A., and Tomasello, M. (2013). Direct and indirect reputation formation in nonhuman great apes (Pan paniscus, Pan troglodytes, Gorilla gorilla, Pongo pygmaeus) and human children (Homo sapiens). J. Comp. Psychol. 127, 63-75. doi: 10.1037/a0028929

Hinde, R. A. (1976). Relationships and social structure. Man New series 11, $1-17$.

Hinde, R. A. (1992). Developmental psychology in the context of other behavioral sciences. Dev. Psychol. 28, 1018-1029.

Hogan, R., and Blickle, G. (2018). "Socioanalytic theory: basic concepts, supporting evidences, and practical implications" in The SAGE handbook of personality and individual differences. eds. V. Zeigler-Hill and T. K. Shackelford (Thousand Oaks, CA: SAGE), 110-129.

Horner, V., Proctor, D., Bonnie, K. E., Whiten, A., and de Waal, F. B. M. (2010). Prestige affects cultural learning in chimpanzees. PLoS One 5:e10625. doi: 10.1371/journal.pone.0010625

Judge, T. A., Piccolo, R. F., and Kosalka, T. (2009). The bright and dark sides of leader traits: a review and theoretical extension of the leader trait paradigm. Leadersh. Q. 20, 855-875. doi: 10.1016/j.leaqua.2009.09.004

Kalma, A., Visser, L., and Peeters, A. (1993). Sociable and aggressive dominance: personality differences in leadership style? Leadersh. Q. 4, 45-64. doi: 10.1016/1048-9843(93)90003-C

Karagianni, D., and Montgomery, A. J. (2018). Developing leadership skills among adolescents and young adults: a review of leadership programmes. Int. J. Adolesc. Youth 23, 86-98. doi: 10.1080/02673843.2017.1292928

Keltner, D., Gruenfeld, D. H., and Anderson, C. (2003). Power, approach, and inhibition. Psychol. Rev. 110, 265-284. doi: 10.1037/0033-295X.110.2.265

King, A., Douglas, C., Huchard, E., Isaac, N., and Cowlishaw, G. (2008). Dominance and affiliation mediate despotism in a social primate. Curr. Biol. 18, 1833-1838. doi: 10.1016/j.cub.2008.10.048

King, A. J., and Sueur, C. (2011). Where next? Group coordination and collective decision making by primates. Int. J. Primatol. 32, 1245-1267. doi: 10.1007/ s10764-011-9526-7

Knott, C. D., Thompson, M. E., Stumpf, R. M., and McIntyre, M. H. (2010). Female reproductive strategies in orangutans, evidence for female choice and counterstrategies to infanticide in a species with frequent sexual coercion. Proc. R. Soc. B Biol. Sci. 277, 105-113. doi: 10.1098/rspb.2009.1552

Koski, S. E. (2011). Social personality traits in chimpanzees: temporal stability and structure of behaviourally assessed personality traits in three captive populations. Behav. Ecol. Sociobiol. 65, 2161-2174. doi: 10.1007/s00265011-1224-0

Kulahci, I., Ghazanfar, A. A., Daniel, I., and Rubenstein, D. I. (2018). Knowledgeable lemurs become more central in social networks. Curr. Biol. 28, 1306-1310. doi: 10.1016/j.cub.2018.02.079

Kulik, L., Muniz, L., Mundry, R., and Widdig, A. (2012). Patterns of interventions and the effect of coalitions and sociality on male fitness. Mol. Ecol. 21, 699-714. doi: 10.1111/j.1365-294X.2011.05250.x

Kummer, H. (1978). On the value of social relationships to nonhuman primates: a heuristic scheme. Soc. Sci. Inf. 17, 687-705. doi: 10.1177/053901847801700418

Laal, M., and Ghodsi, S. M. (2012). Benefits of collaborative learning. Procedia Soc. Behav. Sci. 31, 486-490. doi: 10.1016/j.sbspro.2011.12.091

Leca, J. -B., Gunst, N., Thierry, B., and Petit, O. (2003). Distributed leadership in semifree-ranging white-faced capuchin monkeys. Anim. Behav. 66, 1045-1052. doi: $10.1006 /$ anbe.2003.2276

Lee, S. -H. (2020). Kindergarten teachers' perspectives on young children's bullying roles in relation to dominance and peer relationships: a short-term longitudinal approach in South Korea. Int. J. Environ. Res. Public Health 17:1734. doi: 10.3390/ijerph17051734

Lehmann, J., and Ross, C. (2011). Baboon (Papio anubis) social complexity-a network approach. Am. J. Primatol. 73, 775-789. doi: 10.1002/ajp.20967

Leinfelder, I., De Vries, H., Deleu, R., and Nelissen, M. (2001). Rank and grooming reciprocity among females in a mixed-sex group of captive hamadryas baboons. Am. J. Primatol. 55, 25-42. doi: 10.1002/ajp.1036

Lewis, R. J. (2002). Beyond dominance: the importance of leverage. Q. Rev. Biol. 77, 149-164. doi: 10.1086/343899

Lewis, R. J. (2018). Female power in primates and the phenomenon of female dominance. Annu. Rev. Anthropol. 47, 533-551. doi: 10.1146/annurevanthro-102317-045958
Liu, W., Su, T., Tian, L., and Huebner, E. S. (in press). Prosocial behavior and subjective well-being in school among elementary school students: the mediating roles of the satisfaction of relatedness needs at school and selfesteem. Appl. Res. Qual. Life. doi: 10.1007/s11482-020-09826-1

Massen, J. J. M., Luyten, I. J. A. F., Spruijt, B. M., and Sterck, E. H. M. (2011). Benefiting friends or dominants: prosocial choices mainly depend on rank position in long-tailed macaques (Macaca fascicularis). Primates 52, 237-247. doi: 10.1007/s10329-011-0244-8

Massen, J. J. M., Overduin-de Vries, A. M., de Vos-Rouweler, A. J. M., Spruijt, B. M., Doxiadis, G. G. M., and Sterck, E. H. M. (2012). Male mating tactics in captive rhesus macaques (Macaca mulatta): the influence of dominance, markets, and relationship quality. Int. J. Primatol. 33, 73-92. doi: 10.1007/s10764-011-9552-5

Massen, J. J. M., Sterck, E. H. M., and De Vos, H. (2010). Close social associations in animals and humans: functions and mechanisms of friendship. Behaviour 147, 1379-1412. doi: 10.1163/000579510X528224

Muller, M. N., Thompson, M. E., Kahlenberg, S. M., and Wrangham, R. W. (2011). Sexual coercion by male chimpanzees shows that female choice may be more apparent than real. Behav. Ecol. Sociobiol. 65, 921-933. doi: 10.1007/ s00265-010-1093-y

Nishida, T., and Hosaka, K. (1996). "Coalition strategies among adult male chimpanzees of the Mahale Mountains, Tanzania" in Great ape societies. eds. W. C. McGrew, L. Marchant and T. Nishida (Cambridge: Cambridge University Press), 114-134.

Noë, R., and Hammerstein, P. (1994). Biological markets: supply and demand determine the effect of partner choice in cooperation, mutualism and mating. Behav. Ecol. Sociobiol. 35, 1-11. doi: 10.2307/4600969

Noë, R., Van Schaik, C. P., and van Hooff, J. A. R. A. M. (1991). The market effect: an explanation for pay-off asymmetries among collaborating animals. Ethology 87, 97-118.

Nowak, M. A., and Sigmund, K. (1998). Evolution of indirect reciprocity by image scoring. Nature 393, 573-577.

Olthof, T., Goossens, F. A., Vermande, M. M., Aleva, E. A., and Van der Meulen, M. (2011). Bullying as strategic behavior: relations with desired and acquired dominance in the peer group. J. Sch. Psychol. 49, 339-359. doi: $10.1016 /$ j.jsp.2011.03.003

Ostner, J., and Schülke, O. (2014). The evolution of social bonds in primate males. Behaviour 151, 871-906. doi: 10.1163/1568539X-00003191

Ostrov, J. M., and Guzzo, J. L. (2015). Prospective associations between prosocial behavior and social dominance in early childhood: are sharers the best leaders? J. Genet. Psychol. 176, 130-138. doi: 10.1080/00221325.2015. 1018860

Overduin-de Vries, A. M., de Vries, H., Vermande, M. M., Reijntjes, A. H. A., and Sterck, E. H. M. (2020). Both aggressive and affiliative behaviour facilitate resource access in high-ranking female long-tailed macaques (Macaca fascicularis). Behaviour 157, 267-287. doi: 10.1163/1568539X-bja10001

Palombit, R. A., Seyfarth, R. M., and Cheney, D. L. (1997). The adaptive value of "friendships" to female baboons: experimental and observational evidence. Anim. Behav. 54, 599-614. doi: 10.1006/anbe.1996.0457

Pellegrini, A. D. (2008). The roles of aggressive and affiliative behaviors in resource control: a behavioral ecological perspective. Dev. Rev. 28, 461-487. doi: 10.1016/j.dr.2008.03.001

Pellegrini, A. D., Roseth, C. J., Ryzin, M. J. V., and Solberg, D. W. (2011). "Popularity as a form of social dominance: an evolutionary perspective" in Popularity in the peer system. eds. A. H. N. Cillessen, D. Schwartz and L. Mayeux (New York, NY: Guilford), 123-139.

Perry, S. (2011). Social traditions and social learning in capuchin monkeys (Cebus). Philos. Trans. R Soc. Lond. B Biol. Sci. 366, 988-996. doi: 10.1098/ rstb.2010.0317

Petit, O., and Bon, R. (2010). Decision-making processes: the case of collective movements. Behav. Process. 84, 635-647. doi: 10.1016/j.beproc.2010. 04.009

Polanin, J. R., Espelage, D. L., and Pigott, T. D. (2012). A meta-analysis of school-based bullying prevention programs' effects on bystander intervention behavior. Sch. Psychol. Rev. 41, 47-65. doi: 10.1080/02796015.2012.12087375

Polman, H., Orobio de Castro, B., Thomaes, S., and Van Aken, M. (2009). New directions in measuring reactive and proactive aggression: validation of a teacher questionnaire. J. Abnorm. Child Psychol. 37, 183-193. doi: $10.1007 / \mathrm{s} 10802-008-9266-0$ 
Pusey, A. (2012). "Magnitude and sources of variation in female reproductive performance" in The evolution of primate societies. eds. J. C. Mitani, J. Call, P. M. Kappeler, R. A. Palombit and J. B. Silk (Illinois: University of Chicago Press), 343-366.

Reijntjes, A., Vermande, M. M., Olthof, T., Goossens, F. A., Van de Schoot, R., Aleva, L., et al. (2013a). Developmental trajectories of bullying and social dominance in youth. Child Abuse Negl. 37, 224-234. doi: 10.1016/j. chiabu.2012.12.004

Reijntjes, A., Vermande, M. M., Olthof, T., Goossens, F. A., Van de Schoot, R., Aleva, L., et al. (2013b). Costs and benefits of bullying in the context of the peer group: a three wave longitudinal analysis. J. Abnorm. Child Psychol. 41, 1217-1229. doi: 10.1007/s10802-013-9759-3

Reijntjes, A., Vermande, M., Olthof, T., Goossens, F. A., Vink, G., Aleva, L., et al. (2018). Differences between resource control types revisited: a short term longitudinal study. Soc. Dev. 27, 187-200. doi: 10.1111/sode.12257

Roseth, C. J., Pellegrini, A. D., Dupuis, D. N., Bohn, C. M., Hickey, M. C., Hilk, C. L., et al. (2011). Preschoolers' bistrategic resource control, reconciliation, and peer regard. Soc. Dev. 20, 185-211. doi: 10.1111/j.1467-9507.2010.00579.x

Rowe, A. K., Li, J. -H., Sun, L., Sheeran, L. K., Wagner, R. S., Xia, D. -P., et al. (2018). Collective decision making in Tibetan macaques: how followers affect the rules and speed of group movement. Anim. Behav. 146, 51-61. doi: 10.1016/j.anbehav.2018.10.002

Salmivalli, C., Karnä, A., and Poskiparta, E. (2010). "From peer putdowns to peer support: a theoretical model and how it translated into a national anti-bullying program" in Handbook of bullying in schools: An international perspective. eds. S. R. Jimerson, S. M. Swearer and D. L. Espelage (New York, NY: Routledge), 441-454

Santos, A. J., and Vaughn, B. E. (2018). "Socioethological/developmental principles and perspectives on peer interactions, relationships, and groups from early childhood through adolescence" in Handbook of peer interactions, relationships, and groups. eds. W. M. Bukowski, B. Laursen and K. H. Rubin (New York, NY: Guildford Press), 23-44.

Sapolsky, R. M. (2005). The influence of social hierarchy on primate health. Science 308, 648-652. doi: 10.1126/science.1106477

Schaub, H. (1995). Dominance fades with distance: an experiment on food competition in long-tailed macaques (Macaca fascicularis). J. Comp. Psychol. 109, 196-202.

Schino, G. (2001). Grooming, competition and social rank among female primates: a meta-analysis. Anim. Behav. 62, 265-271. doi: 10.1006/ anbe.2001.1750

Schino, G. (2007). Grooming and agonistic support: a meta-analysis of primate reciprocal altruism. Behav. Ecol. 18, 115-120. doi: 10.1093/beheco/arl045

Schino, G., and Aureli, F. (2009). "Reciprocal altruism in primates. Partner choice, cognition, and emotions" in Advances in the study of behavior. 1st Edn. Vol. 39. Elsevier Inc.

Schino, G., Di Sorrentino, E. P., and Tiddi, B. (2007). Grooming and coalitions in Japanese macaques (Macaca fuscata): partner choice and the time frame reciprocation. J. Comp. Psychol. 121, 181-188. doi: 10.1037/0735-7036. 121.2.181

Seyfarth, R. M. (1977). A model of social grooming among adult female monkeys. J. Theor. Biol. 65, 671-698. doi: 10.1016/0022-5193(77)90015-7

Seyfarth, R. M., and Cheney, D. L. (2012). The evolutionary origins of friendship. Annu. Rev. Psychol. 63, 153-177. doi: 10.1146/annurev-psych-120710-100337

Seyfarth, R. M., Silk, J. B., and Cheney, D. L. (2012). Variation in personality and fitness in wild female baboons. Proc. Natl. Acad. Sci. U. S. A. 109, 16980-16985. doi: 10.1073/pnas.1210780109

Silk, J. B. (2002). Using the "F"-word in primatology. Behaviour 139, 421-446. doi: $10.1163 / 156853902760102735$

Silk, J. B., Alberts, S. C., and Altmann, J. (2006b). Social relationships among adult female baboons (Papio cynocephalus) II. Variation in the quality and stability of social bonds. Behav. Ecol. Sociobiol. 61, 197-204. doi: 10.1007/ s00265-006-0250-9

Silk, J. B., Altmann, J., and Alberts, S. C. (2006a). Social relationships among adult female baboons (Papio cynocephalus) I. Variation in the strength of social bonds. Behav. Ecol. Sociobiol. 61, 183-195. doi: 10.1007/s00265-0060249-2

Silk, J. B., Beehner, J. C., Bergman, T. J., Crockford, C., Engh, A. L., Moscovice, L. R., et al. (2010). Strong and consistent social bonds enhance the longevity of female baboons. Curr. Biol. 20, 1359-1361. doi: 10.1016/j.cub.2010.05.067
Smith, J. E., Gavrilets, S., Borgerhoff Mulder, M., Hooper, P. L., El Mouden, C., Nettle, D., et al. (2016). Leadership in mammalian societies: emergence, distribution, power, and payoff. Trends Ecol. Evol. 31, 54-66. doi: 10.1016/j. tree. 2015.09.013

Smuts, B. B., and Smuts, R. W. (1993). Male-aggression and sexual coercion of females in nonhuman primates and other mammals: evidence and theoretical implications. Adv. Study Behav. 22, 1-63.

Stolz, S., Cillessen, A. H. N., Van den Berg, Y. H. M., and Gommans, R. (2016). Popularity differentially predicts reactive and proactive aggression in early adolescence. Aggress. Behav. 42, 29-40. doi: 10.1002/ab.21603

Strayer, F. F. (1989). "Co-adaptation within the early peer group: a psychobiological study of early competence" in Social competence in developmental perspective. eds. B. Schneider, G. Attili, J. Nadel and R. Weisman (Dordrecht, Netherlands: Kluwer), 145-174.

Strayer, F. F., and Strayer, J. (1976). An ethological analysis of social agonism and dominance relations among preschool children. Child Dev. 47, 980-989.

Stump, K. N., Ratliff, J. M., Wu, Y. P., and Hawley, P. H. (2009). "Theories of social competence from the top-down to the bottom-up: a case for considering foundational human needs" in Social behavior and skills in children. ed. J. L. Matson (New York, NY: Springer), 23-37.

Sueur, C., Petit, O., De Marco, A., Jacobs, A. T., Watanabe, K., and Yjierrry, B. (2011). A comparative network analysis of social style in macaques. Anim. Behav. 82, 845-852. doi: 10.1016/j.anbehav.2011.07.020

Sussman, R. W., Garber, P. A., and Cheverud, J. M. (2005). Importance of cooperation and affiliation in the evolution of primate sociality. Am. J. Phys. Anthropol. 128, 84-97. doi: 10.1002/ajpa.20196

Swift, L. E., Hubbard, J. A., Bookhout, M. K., Grassettia, S. N., Smith, M. A., and Morrow, M. T. (2017). Teacher factors contributing to dosage of the KiVa anti-bullying program. J. Sch. Psychol. 65, 102-115. doi: 10.1016/j. jsp.2017.07.005

Thompson, N. A. (2019). Understanding the links between social ties and fitness over the life cycle in primates. Behaviour 156, 859-908. doi: $10.1163 / 1568539 X-00003552$

Trivers, R. L. (1971). The evolution of reciprocal altruism. Q. Rev. Biol. 46, 35-57.

van de Waal, E., Renevey, N., Favre, C. M., and Bshary, R. (2010). Selective attention to philopatric models causes directed social learning in wild vervet monkeys. Proc. R. Soc. B Biol. Sci. 277, 2105-2111. doi: 10.1098/ rspb.2009.2260

van den Berg, Y. H. M., Burk, W. J., and Cillessen, A. H. N. (2019). The functions of aggression in gaining, maintaining, and losing popularity during adolescence: a multiple-cohort design. Dev. Psychol. 55, 2159-2168. doi: $10.1037 /$ dev0000786

van Noordwijk, M. A., and Van Schaik, C. P. (1999). The effects of dominance rank and group size on female lifetime reproductive success in wild longtailed macaques, Macaca fascicularis. Primates 40, 105-130. doi: 10.1007/ BF02557705

van Schaik, C. P. (1989). "The ecology of social relationships among female primates" in Comparative socioecology, the behavioural ecology of humans and other mammals. eds. V. Standen and R. Foley (Oxford: Blackwells), 195-218.

Vaughn, B. E., and Santos, A. J. (2009). "Affiliation and dominance in preschool groups" in Handbook of peer interactions, relationships, and groups. eds. K. H. Rubin, W. M. Bukowski and B. Laursen (New York, NY: Guilford)

Vermande, M. M., Gilholm, P. A., Reijntjes, A. H. A., Hessen, D. J., Sterck, E. H. M., and Overduin-de Vries, A. M. (2018). Is inspiring group members an effective predictor of social dominance in early adolescence? Direct and moderated effects of behavioral strategies, social skills, and gender on resource control and popularity. J. Youth Adolesc. 47, 1813-1829. doi: 10.1007/s10964-0180830-9

Wang, X., Sun, L., Sheeran, L. K., Sun, B. -H., Zhang, Q. -X., Zhang, D., et al. (2016). Social rank versus affiliation: which is more closely related to leadership of group movements in Tibetan macaques (Macaca thibetana)? Am. J. Primatol. 78, 816-824. doi: 10.1002/ajp.22546

Wasserman, S., and Faust, K. (1994). Social network analysis: Methods and applications. New York, NY: Cambridge University Press.

Watts, D. P. (2000). "Mountain gorilla habitat use strategies and group movements" in On the move. eds. S. Boinski and P. A. Garber (Chicago: University of Chicago Press), 351-374. 
Watts, D. P. (2010). "Dominance, power, and politics in nonhuman and human primates" in Mind the gap. Tracing the origins of human universals. eds. P. M. Kappeler and J. B. Silk (Berlin: Springer-Verlag), 109-138.

Wooddell, L. J., Kaburu, S. S., and Dettmer, A. M. (2019). Dominance rank predicts social network position across developmental stages in rhesus monkeys. Am. J. Primatol. e23024. doi: 10.1002/ajp.23024 [Epub ahead of print] Wooddell, L. J., Kaburu, S. S., Murphy, A. M., Suomi, S. J., and Dettmer, A. M. (2017). Rank acquisition in rhesus macaque yearlings following permanent maternal separation: the importance of the social and physical environment. Dev. Psychobiol. 59, 863-875. doi: 10.1002/dev.21555

Wrangham, R. W. (1980). An ecological model of female-bonded primate groups. Behaviour 75, 262-300.

Zarbatany, L., Ellis, W. E., Chen, X., Kinal, M., and Boyko, L. (2019). The moderating role of clique hierarchical organization on resource control by central clique members. J. Youth Adolesc. 48, 359-371. doi: 10.1007/ s10964-018-0972-9

Conflict of Interest: The authors declare that the research was conducted in the absence of any commercial or financial relationships that could be construed as a potential conflict of interest.

Copyright $\odot 2020$ Vermande and Sterck. This is an open-access article distributed under the terms of the Creative Commons Attribution License (CC BY). The use, distribution or reproduction in other forums is permitted, provided the original author(s) and the copyright owner(s) are credited and that the original publication in this journal is cited, in accordance with accepted academic practice. No use, distribution or reproduction is permitted which does not comply with these terms. 